\title{
EDITORIAL
}

\section{Uniform Requirements for Manuscripts Submitted to Biomedical Journals}

Although the Journal of the Royal Army Medical Corps agreed some years ago to receive manuscripts prepared in accordance with the requirements proposed by the International Committee of Medical Journal Editors (The Vancouver Group), the publication of the third edition of these requirements in 1988 found the $\mathrm{J} R$ Army Med Corps somewhat out of step. This has now been corrected and prospective authors should note the revised "instructions to authors" published in this edition. These new requirernents come into force immediately and will be evident in the October issue of 1990. The full details of the current requirements may be found in the reference given in "instructions to authors". A summary of the main relevant requirements is given below.

\section{Summary of Requirements}

Type the manuscript double spaced, including title page, abstract, text, acknowledgements, references, tables and legends.

Each manuscript component should be on a new page, in the following sequence:

Title page

Abstract and key words

Text

Acknowledgements

References

Tables: each table, complete with title and footnotes on a separate page.

Legends for illustrations

Illustrations must be good-quality, unmounted glossy prints usually 127 by $173 \mathrm{~mm}$ ( 5 by 7 in) but no larger than 203 by $254 \mathrm{~mm}$ ( 8 by 10 in).

The submitted manuscript should be accompanied by a covering letter with permission to reproduce previously published materials or to use illustrations that may identify human subjects.

Authors should keep copies of everything submitted.

\section{Preparation of Manuscript}

Type the manuscript on white bond paper, A4 (212 by $297 \mathrm{~mm}$ ), with margins of at least $25 \mathrm{~mm}$ (1 inch). Type only on one side of the paper. Number pages consecutively, beginning with the title page. Type the page number in the upper or lower right-hand corner of each page.

\section{Title Page}

The title page should carry 1) the title of the article, which should be concise but informative; 2) the first name, middle initial, and last name of each author, with highest academic degree(s) and institutional affiliation;
3) name of department(s) and institution(s) to which the work should be attributed; 4) disclaimers, if any;离 5) name and address of author responsible for corres- $\overrightarrow{0}$ pondence about the manuscript; 6) name and address of author to whom requests for reprints should be $\overline{\bar{p}}$ addressed, or statement that reprints will not be $\widehat{\varnothing}$ available from the author; 7) the source(s) of support in the form of grants, equipment, drugs, or all of these; and ${ }^{\text {es }}$ 8) a short running head or footline of no more than $40 \vec{\circ}$ characters (count letters and spaces) placed at the foot $\vec{\overrightarrow{ }}$ of the title page and identified.

\section{Authorship}

All persons designated as authors should qualify for authorship. Each author should have participated $\vec{\sigma}$ sufficiently in the work to take public responsibility for the content.

Authorship credit should be based only on substantial contributions to (a) conception and design, or analysis? and interpretation of data; (b) drafting the article or revising it critically for important intellectual conter奥; and on (c) final approval of the version to be published. Conditions (a), (b), and (c) must all be met. Particip tion solely in the acquisition of funding or the collection of data does not justify authorship. General supervision. of the research group is also not sufficient for authorship. Any part of an article critical to its m稳 conclusions must be the responsibility of at least ofeco author.

A paper with corporate (collective) authorship must $\stackrel{\mathbb{2}}{\mathscr{D}}$ specify the key persons responsible for the article; others $\overrightarrow{\vec{O}}$ contributing to the work should be recognised 3 separately (see Acknowledgements and Other贾 Information).

The editors may require authors to justify the assignment of authorship.

\section{Abstract and Key Words}

'The second page should carry an abstract of no more@ than 150 words. The abstract should state the purposes? of the study or investigation; basic procedures (selection? of study subjects or experimental animals, observationaland analytic methods); main findings (give specific data and their statistical significance, if possible); and the principal conclusions.

Below the abstract, provide, and identify as such, 3 to $\frac{7}{2}$ 10 key words or short phrases that will assist indexers in cross-indexing your article and that may be published with the abstract. Use terms from the Medical Subject Headings (MeSH) list of Index Medicus; if suitable $\mathrm{MeSH}$ terms are not yet available for recentlyc introduced terms, present terms may be used. 
Text

The text of observational and experimental articles is usually - but not necessarily - divided into sections with the headings Introduction, Methods, Results, and Discussion. Long articles may need subheadings within some sections to clarify their content, especially the Results and Discussion sections. Other types of articles such as case reports, reviews, and editorials are likely to need other formats. Authors should consult individual journals for further guidance.

Introduction: State the purpose of the article. Summarize the rationale for the study or observation. Give only strictly pertinent references, and do not review the subject extensively. Do not include data or conclusions from the work being reported.

Methods: Describe your selection of the observational or experimental subjects (patients or experimental animals, including controls) clearly. Identify the methods, apparatus (manufacturer's name and address within parenthesis marks [round brackets]), and procedures in sufficient detail to allow other workers to reproduce the results. Give references to established methods, including statistical methods (see below); provide references and brief descriptions for methods that have been published but are not well known; describe new or substantially modified methods, give reasons for using them, and evaluate their limitations. Identify precisely all drugs and chemicals used, including generic name(s), dose(s), and route(s) of administration.

Ethics: When reporting experiments on human subjects, indicate whether the procedures followed were in accordance with the ethical standards of the responsible committee on human experimentation (institutional or regional) or with the Helsinki Declaration of 1975, as revised in 1983. Do not use patients' names, initials, or hospital numbers, especially in any illustrative material. When reporting experiments on animals indicate whether the institution's or the National Research Council's guide for, or any national law on, the care and the use of laboratory animals was followed.

Statistics: Describe statistical methods with enough detail to enable a knowledgeable reader with access to the original data to verify the reported results. When possible, quantify findings and present them with appropriate indicators of measurement error or uncertainty (such as confidence intervals). Avoid sole reliance on statistical hypothesis testing, such as the use of $P$ values, which fails to convey important quantitative information. Discuss eligibility of experimental subjects. Give details about randomization. Describe the methods for, and success of, any blinding of observations. Report losses to observation (such as dropouts from a clinical trial). References for study design and statistical methods should be to standard works (with pages stated) when possible rather than to papers where designs or methods were originally reported. Specify any general-use computer programs used.

Put general descriptions of methods in the Methods section. When data are summarized in the Results section, specify the statistical methods and analyze them. Restrict tables and figures to those needed to explain the argument of the paper and to assess its support. Use graphs as an alternative to tables with many entries; do not duplicate data in graphs and tables. Avoid non-technical uses of technical terms in statistics, such as "random" (which implies a randomizing device), "normal", "significant", "correlation", and "sample". Define statistical terms, abbreviations, and most symbols.

Results: Present your results in logical sequence in the text, tables and illustrations. Do not repeat in the text all the data in the tables, emphasize or summarize only important observations.

Discussion: Emphasize the new and important aspects of the study and conclusions that follow from them. Do not repeat in detail data or other material given in the Introduction or the Results section. Include in the Discussion section the implications of the findings and their limitations, including implications for future research. Relate the observations to other relevant studies. Link the conclusions with the goals of the studyo but avoid unqualified statements and conclusions nok completely supported by your data. Avoid claiming priority and alluding to work that has not been $\vec{P}$ completed. State new hypotheses when warranted, but clearly label them as such. Recommendations, when appropriate, may be included.

\section{Acknowledgements}

At an appropriate place in the article (title-page, footnote or appendix to the text; see the journal's requirement) one or more statements should specify: (a) contributions that need acknowledging but do not justify authorship, such as general support by a departmental chairman; (b) acknowledgements of technical help; (c) acknowledgements of financial and material support, specifying the nature of the support; (d) financial relationships that may pose a conflict of interest.

Persons who have contributed intellectually to the paper but whose contributions do not justify authorship may be named and their function or contribution described, for example, "scientific adviser", "critical review of study proposal", "data collection", "participation in clinical trial". Such persons must have given their permission to be named. Authors are responsible for obtaining written permission from persons acknowledged by name because readers may infer their 
endorsement of the data and conclusions.

Technical help should be acknowledged in a paragraph separate from those acknowledging other contributions.

\section{References}

Number references consecutively in the order in which they are first mentioned in the text. Identify references in text, tables, and legends by Arabic numerals within parenthesis marks. References cited only in tables or in legends to figures should be numbered in accordance with a sequence established by the first identification in the text of the particular table or illustration.

Use the style of the examples below, which are based on the formats used by the US National Library of Medicine in Index Medicus. The titles of journals should be abbreviated according to the style used in Index Medicus. Consult List of Journals Indexed in Index Medicus, published annually.

Try to avoid using abstracts as references; "unpublished observations" and "personal communications" may not be used as references, although references to written, not oral, communication may be inserted (within parenthesis marks) in the text. Include among the references papers accepted but not yet published; designate the journal and add "in press" (within parenthesis marks). Information from manuscripts submitted but not yet accepted should be cited in the text as "unpublished observations" (within parenthesis marks).

The references must be verified by the author(s) against the original documents.

Examples of correct forms of references are given below.

\section{Journals}

1. Standard Journal Article (List all authors when six or less; when seven or more, list only first three and add et al.)

You CH, Lee KY, Chey RY, Menguy R. Electrogastrographic study of patients with unexplained nausea, bloating and vomiting. Gastronenterology 1980; 79:311-4.

\section{Corporate Author}

The Royal Marsden Hospital Bone-Marrow Transplantation Team. Failure of syngeneic bone-marrow graft without preconditioning in post-hepatitis marrow aplasia. Lancet $1977 ; 2: 242-4$.

3. No Author Given

Anonymous. Coffee drinking and cancer of the pancreas [Editorial]. Br Med $J$ 1981; 283:628.

\section{Books and Other Monographs}

\section{Personal Author(s)}

Eisen HN. Immunology: an introduction to molecular and cellular principles of the immune response. 5th ed. New York: Harper and Row,
1974:406.

5. Editor, Compiler, Chairman as Author Dausset J, Colombani J, eds. Histocompatibility? testing 1972. Copenhagen: Munksgaard, 1973: 12-8.

6. Chapter in a Book

Weinstein L, Swartz MN. Pathogenic properties of invading micro-organisms. In: Sodeman WA $\mathrm{Jr}$, Sodeman WA, eds. Pathologic physiology: $\overline{\bar{m}}$ mechanisms of disease. Philadelphia: WB Saunders,, $1974 ; 457-72$.

\section{Tables}

Type each table spaced on a separate sheet. Do not submit tables as photographs. Number tables consecu- $-\infty$ tively in the order of their first citation in the text and $\overrightarrow{0}$ supply a brief title for each. Give each column a short or $\overrightarrow{-}$ abbreviated heading. Place explanatory matter in $\omega_{\odot}^{\omega}$ footnotes, not in the heading. Explain in footnotes all non-standard abbreviations that are used in each table. 3 For footnotes, use the following symbols, in this? sequence: ${ }^{*}, \dagger, \ddagger, \S, \|, \mathbb{I},{ }^{* *}, \dagger \dagger, \ldots$

Identify statistical measures of variations such as standard deviation and standard error of the mean.

Do not use internal horizontal and vertical ruling.

Be sure that each table is cited in the text.

If you use data from another published or unpublish $\stackrel{\nabla}{\bar{\alpha} d}$ source, obtain permission and acknowledge fully.

\section{Illustrations}

Submit the required number of complete sets figures. Figures should be professionally drawn afd? photographed; freehand or typewritten lettering 9 so unacceptable. Instead of original drawings, roentgens grams, and other material, send sharp, glossy black-anewhite photographic prints, usually 127 by $173 \mathrm{~mm}$ ( 5 byg 7 in) but not larger than 203 by $254 \mathrm{~mm}$ ( 8 by 10 in). Letters, numbers, and symbols should be clear and even throughout, and of sufficient size that when reduced for? publication each item will still be legible. Titles and detailed explanations belong in the legends for illustra tions, not on the illustrations themselves.

Each figures should have a label pasted on its back indicating the number of the figure, author's name, and the top of the figure. Do not write on the back of the figures, or scratch or mark them using paper clips. Dos not bend figures or mount them on cardboard.

Photomicrographs must have internal scale markers. Symbols, arrows, or letters used in the photomicro? graphs should contrast with the background.

If photographs of persons are used, either the subjectse must not be identifiable or their pictures must beo accompanied by written permission to use the photograph.

Figures should be numbered consecutively according to the order in which they have been first cited in the text. If a figure has been published, acknowledge the original source and submit written permission from the copyright holder to reproduce the material. Permissiono

告


is required, irrespective of authorship or publisher, except for documents in the public domain.

\section{Legends for Illustrations}

Type legends for illustrations double spaced, starting on a separate page, with arabic numerals corresponding to the illustrations. When symbols, arrows, numbers, or letters are used to identify parts of the illustrations, identify and explain each one clearly in the legend. Explain internal scale and identify method of staining in photomicrographs.

\section{Units of Measurement}

Measurements of length, height, weight, and volume should be reported in metric units (metre, kilogram litre) or their decimal multiples.

Temperatures should be given in degrees Celsius Blood pressure should be given in millimetres of mercury.

All haematological and clinical chemistry measurements should be reported in the metric system in terms of the International System of Units (SI).

Abbreviations and Symbols

Use only standard abbreviations. Avoid abbreviations in the title and abstract. The full term for which an abbreviation stands should precede its first use in the text unless it is a standard unit of measurement.

\section{ACADEMIC ACHIEVEMENTS}

\author{
ChM (University of Manchester) \\ MRCGP (Distinction) \\ MRCGP
}

FFARCS(I)

FC Anaes

MRCP(UK)

$\operatorname{FRCS}(\mathbf{E d})$

FRCS

DIH

AFOM
Major M K Oak, RAMC

Captain J C Reggler, RAMC

Major P A Laing-Morton, RAMC

Major R J Bisset, RAMC

Major R T A Walker, RAMC

Major M C Gadd, RAMC

Major J P Barrell, RAMC

Captain E MFoster, RAMC

Captain S M Daykin, RAMC

Captain T M Jackson, RAMC

Major A G Kidd, RAMC

Major A G Kidd, RAMC

Captain R W Crabbe, RAMC

Colonel I R Haywood, L/RAMC

Captain G H Muir, RAMC

Captain G W Bowyer, RAMC

Major P A Johnson, RAMC

Major P A Johnson, RAMC

\section{HONORARY CONSULTANTS TO THE ARMY}

Professor J A D Anderson, TD, DL has been appointed Honorary Consultant in Public Health Medicine to the Army with effect from 21 January 1990. 